Research Article

\title{
Synthesis and Characterization of Gallium Oxide/Tin Oxide Nanostructures via Horizontal Vapor Phase Growth Technique for Potential Power Electronics Application
}

\author{
Lester D. Bernardino ${ }^{1,2}$ and Gil Nonato C. Santos $\left.{ }^{1}\right)^{1}$ \\ ${ }^{1}$ Physics Department, De La Salle University, Manila 1004, Philippines \\ ${ }^{2}$ Applied Physics Department, Eulogio "Amang" Rodriguez Institute of Science and Technology, Manila 1008, Philippines \\ Correspondence should be addressed to Lester D. Bernardino; lester_bernardino@dlsu.edu.ph and Gil Nonato C. Santos; \\ gil.santos@dlsu.edu.ph
}

Received 26 June 2020; Revised 17 September 2020; Accepted 5 November 2020; Published 23 November 2020

Academic Editor: Guian Qian

Copyright (c) 2020 Lester D. Bernardino and Gil Nonato C. Santos. This is an open access article distributed under the Creative Commons Attribution License, which permits unrestricted use, distribution, and reproduction in any medium, provided the original work is properly cited.

\begin{abstract}
The monoclinic $\beta$-gallium oxide $\left(\mathrm{Ga}_{2} \mathrm{O}_{3}\right)$ was viewed as a potential candidate for power electronics due to its excellent material properties. However, its undoped form makes it highly resistive. The $\mathrm{Ga}_{2} \mathrm{O}_{3} / \mathrm{SnO}_{2}$ nanostructures were synthesized effectively via the horizontal vapor phase growth (HVPG) technique without the use of a magnetic field. Different concentrations of $\mathrm{Ga}_{2} \mathrm{O}_{3}$ and $\mathrm{SnO}_{2}$ were varied to analyze and describe the surface morphology and elemental composition of the samples using the scanning electron microscopy (SEM) and energy-dispersive X-ray (EDX) spectroscopy, respectively. Meanwhile, the polytype of the $\mathrm{Ga}_{2} \mathrm{O}_{3}$ was confirmed through the Fourier transform infrared (FTIR) spectroscopy. The current-voltage (I-V) characteristics were established using a Keithley 2450 source meter. The resistivity was determined using the van der Pauw technique. The mobility and carrier concentration was done through the Hall effect measurements at room temperature using a 0.30-Tesla magnet. It was observed that there was an increase in the size of the nanostructures, and more globules appeared after the concentration of $\mathrm{SnO}_{2}$ was increased. It was proven that the drop in the resistivity of $\mathrm{Ga}_{2} \mathrm{O}_{3}$ was due to the presence of $\mathrm{SnO}_{2}$. The data gathered were supported by the Raman peak located at $662 \mathrm{~cm}^{-1}$, attributed to the high conductivity of $\beta$ - $\mathrm{Ga}_{2} \mathrm{O}_{3}$. However, the $\varepsilon$-polytype was verified to appear as a result of adding $\mathrm{SnO}_{2}$. All the samples were considered as $n$-type semiconductors. High mobility, low power loss, and low specific on-resistance were attained by the highest concentration of $\mathrm{SnO}_{2}$. Hence, it was clinched as the optimal n-type $\mathrm{Ga}_{2} \mathrm{O}_{3} / \mathrm{SnO}_{2}$ concentration and recommended to be a potential substrate for power electronics application.
\end{abstract}

\section{Introduction}

Silicon-based technology has been the mainstream in power electronics [1]. However, its power devices are approaching their physical limitation [2] when operating at extreme voltage, current, power, and temperature environments, allowing other semiconductor materials to dominate large market sectors untouched by Si-based devices [3]. Consequently, research and development on wide bandgap materials [4] are carried out in the past years so that the volume and weight of power electronic devices can be improved for more extensive applications [5].
Recently, gallium oxide $\left(\mathrm{Ga}_{2} \mathrm{O}_{3}\right)$ gained significant attention as a material for power electronics applications [6] because of its extremely large bandgap [7] in the range of $4.6 \mathrm{eV}$ to $4.9 \mathrm{eV}$, depending on the specific crystal orientation and measurement method [8].

Among the five phases of $\mathrm{Ga}_{2} \mathrm{O}_{3}$, the most studied is the ground state $\beta$ [9] because of its availability and outstanding properties $[10,11]$. Its potential applications range from transparent conducting electrodes to power electronics [12]. The breakdown voltage of $\mathrm{Ga}_{2} \mathrm{O}_{3}$ is $8 \mathrm{MV} / \mathrm{cm}$, which is higher than that of $\mathrm{Si}, \mathrm{SiC}$, and $\mathrm{GaN}$, which makes it suitable for high voltage and high-temperature applications [1]. 
However, the undoped $\beta-\mathrm{Ga}_{2} \mathrm{O}_{3}$ is highly resistive because of its wide bandgap. Electrical property measurements of $\mathrm{Ga}_{2} \mathrm{O}_{3}$ nanowires and nanoribbons have revealed n-type semiconductor behavior [13], which has been attributed to oxygen vacancies $\left(V_{\mathrm{o}}\right)$ or Ga interstitials $[3,14]$. As reported by Varley et al. [15], $V_{\mathrm{o}}$ acts as a deep donor and does not contribute to its conductivity. Hence, doping with elements acting as shallow donors is necessary to enhance its electrical conductivity [16].

Sn was found to be a shallow donor when incorporated into the $\mathrm{Ga}$ site $[15,17-19]$. The mixing of $\mathrm{Ga}$ with $\mathrm{Sn}$ inevitably causes the replacement of $\mathrm{Ga}^{+3}$ ions with $\mathrm{Sn}^{+4}$ ions [20]. The tetravalent $\mathrm{Sn}$ ion is most often chosen as donor dopant [18] since it is also an n-type that enhances the natural conductivity of $\beta-\mathrm{Ga}_{2} \mathrm{O}_{3}[21,22]$ and their ionic radii are close with each other $[18,21]$.

In the past years, a high amount of work was devoted to the growth of the undoped semiconductor nanowires by several approaches. Up to this date, a cost-efficient synthesis technique of manufacturing nanostructure is still a grand challenge [1]. The fabrication of one-dimensional structures gained interests due to their importance in understanding the dependence of properties on the size and dimensionality of materials, and their potential applications as functional building blocks for electrical, optical, and magnetic devices [14]. Although there are several synthesis methodologies, the thermal evaporation using a metal catalyst is a successful route to fabricate semiconducting oxide nanostructure from single nanowires or nanorods to hierarchical nanostructures [23]. Nevertheless, few papers have been reported for the conductivity control of $\beta-\mathrm{Ga}_{2} \mathrm{O}_{3}$ by doping [24]. Experimentally determined results for free charge carrier concentrations and mobility parameters are currently scarce for $\beta-\mathrm{Ga}_{2} \mathrm{O}_{3}$ [25].

The horizontal vapor phase growth (HVPG) is a homedeveloped [26] and low-cost synthesis technique which proved to produce various one-dimensional nanostructures using different starting materials such as $\mathrm{SnO}_{2}[27,28]$, $\mathrm{Fe}_{2} \mathrm{O}_{3}$ [26], and $\mathrm{In}_{2} \mathrm{O}_{3}$ [29]. Recently, undoped nanowires were successfully fabricated by the presence of a magnetic field via HVPG for high-concentration ethanol vapor detection [30]. In this regard, $\mathrm{SnO}_{2}$ was chosen as dopant since there were studies already conducted using HVPG and its small amount was known to increase the electrical conductivity of $\mathrm{Ga}_{2} \mathrm{O}_{3}$ [21].

This pursuit was an initial investigation on the synthesis of $\mathrm{Ga}_{2} \mathrm{O}_{3} / \mathrm{SnO}_{2}$ via the horizontal vapor phase growth (HVPG) technique without the application of the magnetic field. The concentration of $\mathrm{SnO}_{2}$ was varied to determine its effect on the surface morphology and electrical attributes of $\mathrm{Ga}_{2} \mathrm{O}_{3}$ for potential power electronic applications. The characterizations were performed using SEM and EDX, while the polytypes were affirmed through the known peaks of Raman. The I-V curves were uncovered using a two-point probe test and the van der Pauw technique for the electrical resistivity. The Hall effect measurements revealed the carrier concentration and mobility. Additionally, the specific onresistance and power loss were studied for potential power electronics applications.

\section{Experimental Setup}

2.1. Synthesis of $\mathrm{Ga}_{2} \mathrm{O}_{3} / \mathrm{SnO}_{2}$ Nanostructures. This study employed the horizontal vapor phase growth (HVPG) technique patented by Santos et al. [28] for the synthesis of $\mathrm{Ga}_{2} \mathrm{O}_{3} / \mathrm{SnO}_{2}$ nanostructures. The HVPG is a deposition method that follows a spontaneous growth or vapor-solid (VS) process, which employs the evaporation-condensation process at a very low pressure of $10^{-6}$ Torr. The annealing process requires metal oxide material to evaporate at a very high temperature. Subsequently, the vapor nucleates into particles and transports to the substrate. The source material then condenses and deposits on the substrate's surface because of the temperature difference along the silica quartz tube, resulting in the formation of distinct nanomaterials.

Fifty milligrams of $\mathrm{Ga}_{2} \mathrm{O}_{3}$ powder was mixed with or without $\mathrm{SnO}_{2}$ powder purchased from Sigma-Aldrich. The variation of $\mathrm{Ga}_{2} \mathrm{O}_{3}$ and $\mathrm{SnO}_{2}$ was based on the weight percent (wt.\%) ratio of 98:2 used in relation to [31]. Consequently, the mass loadings were named as sample A (100:0 wt.\%) or the asgrown, sample B (99:2 wt.\%), sample C (98:2 wt.\%), and sample D (90:10 wt.\%). The samples were poured in fused-silica quartz tubes and sealed under a high-vacuum system, while the pressure was maintained at $10^{-6}$ Torr. Afterward, the sealed tubes were injected midway through a Thermolyne horizontal tube furnace and then annealed at $1,200^{\circ} \mathrm{C}$ with a ramp time of 40 minutes for 8 hours as shown in Figure 1(a). Regions of interest were assigned according to their position in the furnace during the annealing process. Figure 1(b) shows that zone 1 contained the powder which was positioned inside the furnace. Meanwhile, the middle portion of the tube was designated as zone 2 . The last part of the tube that was completely outside the furnace was designated as zone 3 [27].

As affirmed by [27], the temperature in zone 1 was $1200^{\circ} \mathrm{C}, 353^{\circ} \mathrm{C}$ to $800^{\circ} \mathrm{C}$ in zone 2 , and $63^{\circ} \mathrm{C}$ to $352^{\circ} \mathrm{C}$ in zone 3. After the tubes cooled down, they were removed from the furnace and then ruptured to collect the nanomaterials for characterization. The $\mathrm{Ga}_{2} \mathrm{O}_{3} / \mathrm{SnO}_{2}$ was compared to the initially prepared as-grown specimen.

\subsection{Characterization of $\mathrm{Ga}_{2} \mathrm{O}_{3} / \mathrm{SnO}_{2}$ Nanostructures.} JEOL JFC-1200 fine coater was used to gold $(\mathrm{Au})$ sputter every sample at $50 \mathrm{~mA}$ for 90 seconds to become conductive.

Then, the Au coated samples were subjected to Phenom XL Scanning Electron Microscope equipped with energydispersive X-ray spectroscopy for surface morphology and elemental composition of the nanostructures. Point analyses were performed to know and to verify the elemental contents of the nanostructures and globules. The traditional manual image analysis using Image J was utilized to determine the size of the nanostructures.

The zone where the nanostructures were found was subjected to polytype analysis. The Fourier transform infrared (FTIR) spectroscopy confirmed the occurrence of $\beta-\mathrm{Ga}_{2} \mathrm{O}_{3}$, which was reported by Higashiwaki et al. [1] to be suitable for power electronics applications. Furthermore, FTIR was utilized to know the other $\mathrm{Ga}_{2} \mathrm{O}_{3}$ phases present in the specimens based on their known peaks [32]. 


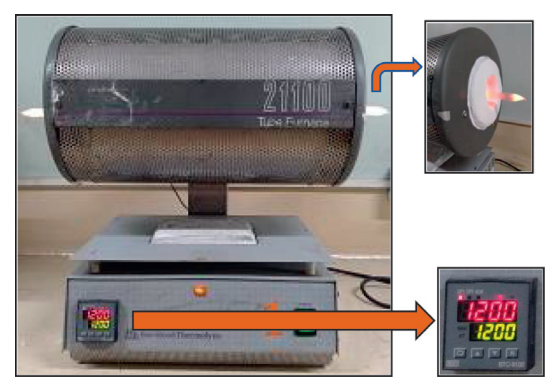

(a)

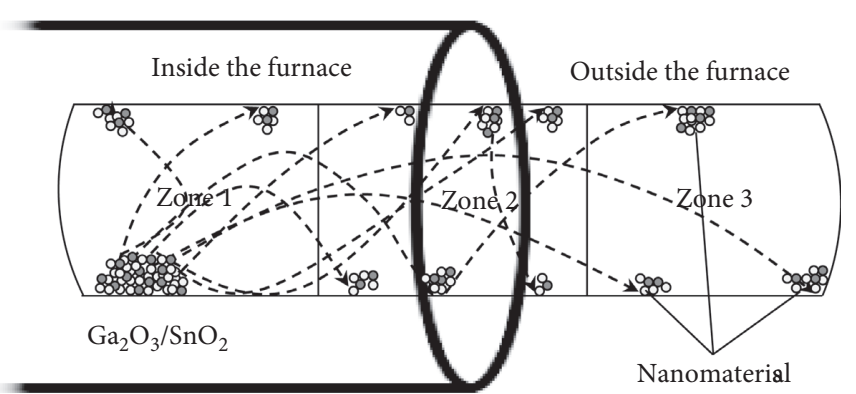

(b)

FIGURE 1: Horizontal vapor phase growth: (a) actual system and (b) setup illustration.

A two-point probe using Keithley 2450 source meter was operated to establish the current-voltage (I-V) characteristics of the samples. The voltage sweep was set to 200 points, while the voltage was varied from $-5.0 \mathrm{~V}$ to $+5.0 \mathrm{~V}$. The resulting current was recorded automatically and plotted by the source meter.

On the other hand, Hall effect and electrical resistivity measurements were carried at room temperature (RT) using the van der Pauw method. The sense terminals of Keithley 2450 Source Meter were used to measure the voltage of the sample under test (SUT), while the force terminals sourced current to SUT. For Hall effect measurement, the method used by Matsumura and Sato [33] was followed where a magnetic field of $0.30 \mathrm{~T}$ was applied in the direction of the sample's thickness, and the change in voltage between the point contacts placed at diagonally opposite corners was measured. Consequently, mobility and carrier concentrations were calculated based on the resistivity and Hall coefficients of each sample.

Both power loss and specific on-resistance were likewise computed based on the applied current and the established value of the electrical resistivity for potential power electronics applications.

\section{Results and Discussion}

3.1. Surface Morphology and Elemental Composition Analyses. The nanostructures presented in Figure 2(a) were excellently viewed at 6,500x magnification showing a pile of bulk and rigid nanostructures. Their size ranged from $4.46 \mu \mathrm{m}$ to $11.357 \mu \mathrm{m}$ and an average of $3.177 \mu \mathrm{m}$. Figure 2(b) shows that $\mathrm{Ga}$ and $\mathrm{O}$ had $32.30 \%$ and $31.20 \%$ compositions, respectively, leading to the ratio of $1: 1$. It can be seen that $\mathrm{Au}$ appeared in the EDX since all the zones were sputtered to make them conductive for surface morphology and elemental analysis. It was noticed that the samples charged up when sputtering was done less than 90 seconds. However, the concentration of Au became more apparent than those of $\mathrm{Ga}$ and O. Similar observations were noticed across all the zones and prepared specimens. No other impurities appeared besides Au.

It was perceived in Figure 3(a) that combinations of straight, crossing, and twisted nanowires were in good agreement with the literature [34]. A manual assessment revealed that their diameter ranged from $52.287 \mathrm{~nm}$ to $167.401 \mathrm{~nm}$ and a mean diameter of $90.976 \mathrm{~nm}$. No nanobelts nor nanorods were observed in this zone. Thicker yields were noticed compared to [34-36]. On the other hand, thinner nanowires were seen compared to [30] using the same deposition technique with an applied magnetic field. Figure 3(b) shows $\mathrm{Ga}$ to $\mathrm{O}$ ratio of approximately $2: 3$.

The deposits found in Figure 2(a) were very similar to those in Figure 4(a) but much smaller considering the fact that they were viewed at the same magnification. Their size ranged from $0.156 \mu \mathrm{m}$ to $2.971 \mu \mathrm{m}$ and a mean size of $0.837 \mu \mathrm{m}$. The ratio of $\mathrm{Ga}$ to $\mathrm{O}$ was not proportionate with $\mathrm{Ga}_{2} \mathrm{O}_{3}$ due to few $\mathrm{Ga}$ atoms. No other impurities appeared in the analysis as seen in Figure 4(b), besides Au.

Figure 5(a) shows the same SEM image taken in relation to [30]. The assessed size of the nanostructures ranged from $233.836 \mathrm{~nm}$ to $998.948 \mathrm{~nm}$ and a mean size of $575.231 \mathrm{~nm}$. A similar ratio was assessed with zone 3 of sample A based on Figure 5(b).

The nanostructures had smoother and straighter morphology but much thicker compared to the as-grown sample. The appearance of globules was evident in all SEM images in Figure 6, which were not seen in the asgrown sample. They were not only attached to the tip of the nanostructures but likewise on its lateral surface [32]. It was likewise examined that the globules fit the nanostructures and none of which fell off onto the substrate due to their sufficient amount. Few globules were seen in the image due to a very small concentration of $\mathrm{SnO}_{2}$. More globules attached to the nanostructures were considered as salient and novel information of this study. The size of the nanostructures ranged from $30.864 \mathrm{~nm}$ to $277.055 \mathrm{~nm}$ with an average of $98.781 \mathrm{~nm}$ and was considered as 1D nanomaterials, specifically nanowires. On the other hand, the size of the globules ranged from $0.575 \mu \mathrm{m}$, while the largest was $6.086 \mu \mathrm{m}$ with an average of $2.336 \mu \mathrm{m}$.

Based on Figure $7(\mathrm{a})$, the ratio of $\mathrm{Ga}$ to $\mathrm{O}$ of the nanostructure was approximately $2: 7$, which was due to the presence of the dopant, while the globule was $1: 6$. According to Jessen et al. [37], the chemical composition of the droplet was purely Sn through the EDS and EDX 


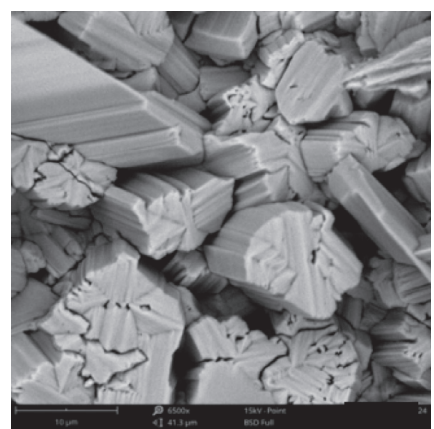

(a)

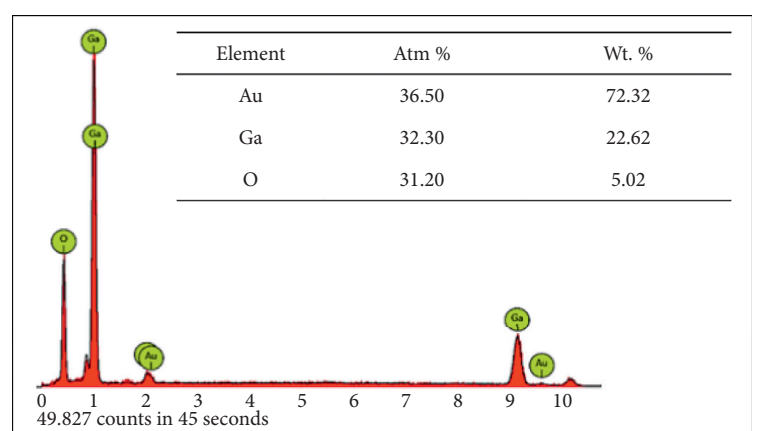

(b)

FIgURE 2: Zone 1. (a) SEM image at 6,500x magnification and (b) EDX spectra of sample A.

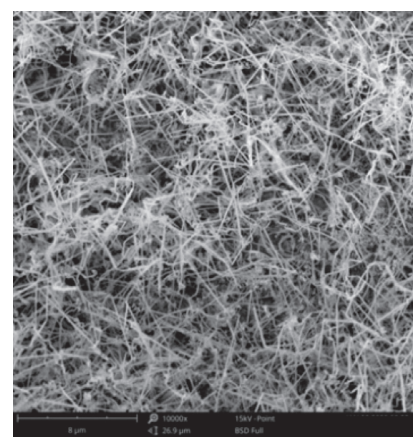

(a)

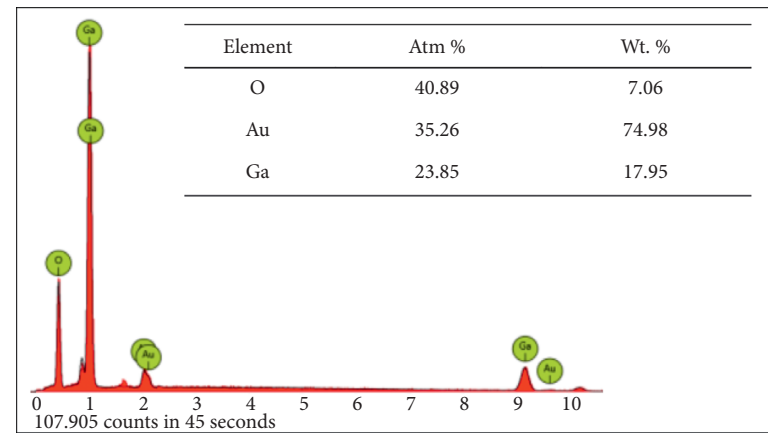

(b)

FIgURE 3: Zone. (a) SEM image at 10,000x magnification and (b) EDX spectra of sample A.

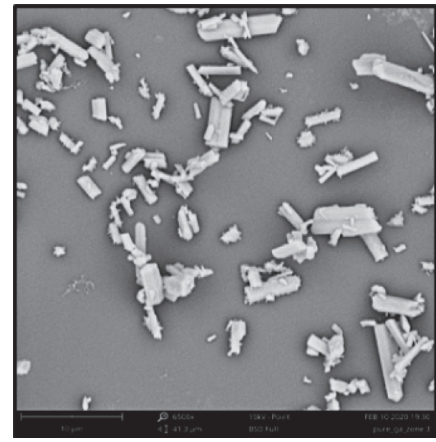

(a)

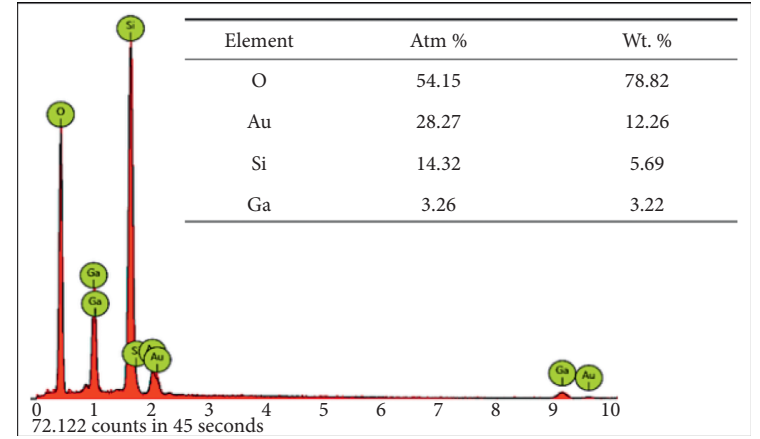

(b)

FIgURE 4: Zone 3. (a) SEM image at 6,500x magnification and (b) EDX spectra of sample A.

analyses; however, this study revealed that the globule was mixed of $\mathrm{Sn}$ and Ga atoms. Consequently, both the nanostructures and globules were comprised of $\mathrm{Ga}, \mathrm{Sn}$, and $\mathrm{O}$ atoms as shown in Figures 7(b) and 7(c).

A similar image is noticed in Figure 8(a) and the asgrown sample, which matches the bulk $\mathrm{Ga}_{2} \mathrm{O}_{3}$ powder, with size ranging from $190 \mathrm{~nm}$ to $1,937 \mathrm{~nm}$ and mean size of $662.265 \mathrm{~nm}$. Zone 3 was found to be Ga deficient due to a very small concentration as seen in Figure 8(b).

Small and large pieces of crystalline nanoblocks are spotted in Figure 9(a) signifying that the $\mathrm{Ga}_{2} \mathrm{O}_{3}$ powder was not melted totally during the deposition. The size of the nanostructures ranged from $248 \mathrm{~nm}$ to $2,364 \mathrm{~nm}$ and an average size of $804.615 \mathrm{~nm}$. As assessed in Figure 9(b), Ga to O ratio was verified to be approximately $2: 3$.

It was observed that more globules of different sizes and twisted nanostructures were present in this concentration compared to sample B. Furthermore, smaller globules positioned at the tip and lateral surface of the nanostructures are noticed in Figures 10(a)-10(c). The size of the nanostructures ranged from $52.305 \mathrm{~nm}$ to $157.893 \mathrm{~nm}$ and an average diameter of $107.274 \mathrm{~nm}$. On the other hand, the 


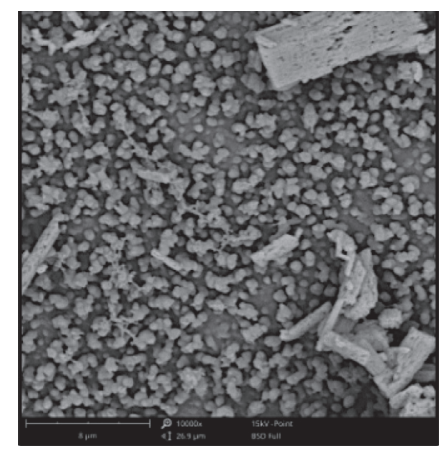

(a)

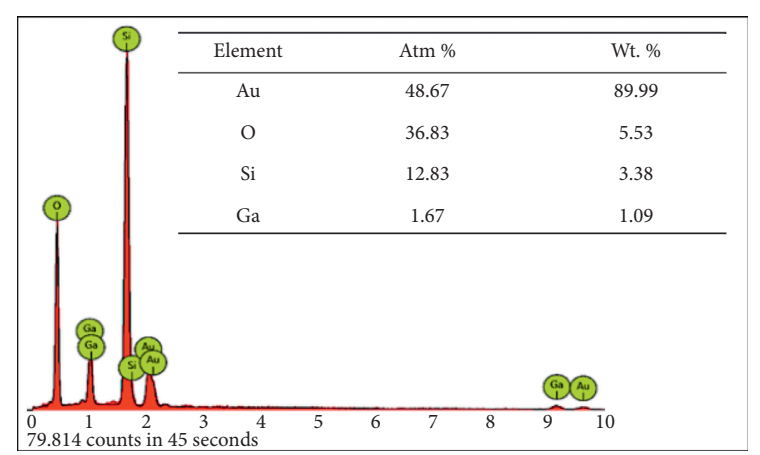

(b)

Figure 5: Zone 1. (a) SEM image and (b) EDX spectra of sample B.

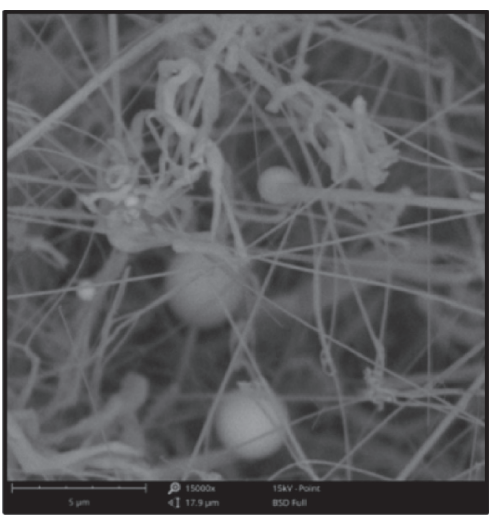

(a)

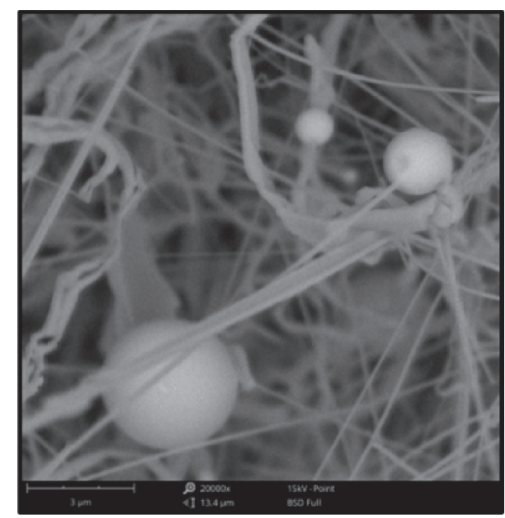

(b)

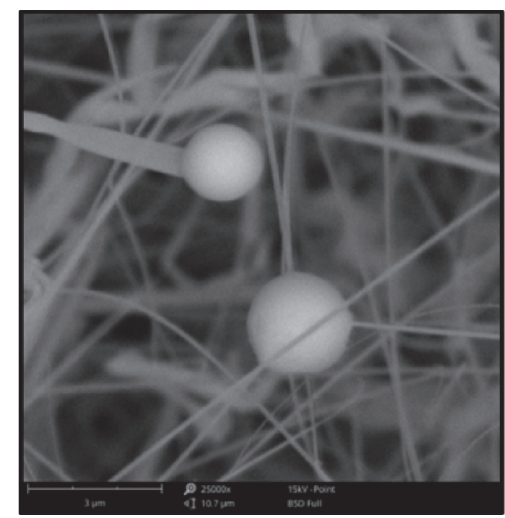

(c)

FIgURE 6: Zone 2 SEM images of sample B at (a) 15,000x, (b) 20,000x, and (c) 25,000x magnification.

assessed diameter of the globules ranged from $0.169 \mu \mathrm{m}$ to $9.782 \mu \mathrm{m}$ and a mean diameter of $2.042 \mu \mathrm{m}$. The quantity of the globules depends on the increase in the concentration of $\mathrm{SnO}_{2}$ to $\mathrm{Ga}_{2} \mathrm{O}_{3}$.

Figure 11(a) reveals that the nanostructures were composed of combined $\mathrm{O}, \mathrm{Sn}$, and $\mathrm{Ga}$ atoms with $34.40 \%$, $6.73 \%$, and $6.34 \%$, respectively. Ga to $\mathrm{O}$ ratio was found to be $2: 11$ as contributed by $\mathrm{SnO}_{2}$. Compared with sample B, the nanostructures' main content was $\mathrm{Ga}$; however, $\mathrm{Sn}$ in this concentration was seen in Figure 11(b). Consistently, the main component of the globule was Sn with $14.44 \mathrm{~atm} \%$ as shown in Figure 11(c).

Since few nanoparticles were found, Figures 12 (a) and 12(b) prove that Ga has the least share of $1.54 \%$ compared with $\mathrm{Au}, \mathrm{O}$, and $\mathrm{Si}$ with $62.31 \%, 24.13 \%$, and $12.02 \%$, respectively. Consequently, Ga to $\mathrm{O}$ ratio was found to be 2 : 12.

Figure 13(a) shows bulk and small nanomaterials with a rigid structure. However, Figure 13(b) proves that this zone was made up of $7.50 \% \mathrm{Ga}$ and $37.98 \% \mathrm{O}$, leading to $\mathrm{Ga}$ to $\mathrm{O}$ ratio of $2: 8$. No other impurities were found in this zone besides $47.18 \% \mathrm{Au}$ and $7.34 \% \mathrm{Si}$.

A similar image is observed in Figure 14(a) and supported by Ga to $\mathrm{O}$ ratio of $5: 2$ based on EDX analysis in
Figure 14(b).

More globules but larger in diameter were produced in this concentration compared with samples $\mathrm{B}$ and C. Figure 15(a) shows an excellent view of a melting nanostructure with a globule attached on its end, while a globule was attached permanently on two nanostructures in Figure 15(b). Meanwhile, it was observed that the nanostructures were not sufficient to hold all the globules permanently in Figure 15(c). It was further noticed that there were many globules compared to nanostructures causing them to fall onto the substrate. Only a small amount of Sn has been shown to incorporate successfully without segregation effectively [22]. The size of the nanostructure ranged from $65.788 \mathrm{~nm}$ to $526.316 \mathrm{~nm}$ and an average diameter of $247.341 \mathrm{~nm}$. On the contrary, the globules' size ranged from $0.521 \mu \mathrm{m}$ to $18.872 \mu \mathrm{m}$ and a mean diameter of $2.725 \mu \mathrm{m}$. The presence of nanorods was significant since the globules were attached to its surface. A huge globule cannot be supported by a single nanostructure. Thus, if the nanostructures were neither aggregated nor thicker, the huge globules just fell off onto the substrate. Due to this reason, the concentration was not further increased.

SEM image shown in Figure 16(a), supported by Figure 16(b), proved that the nanostructures' main 

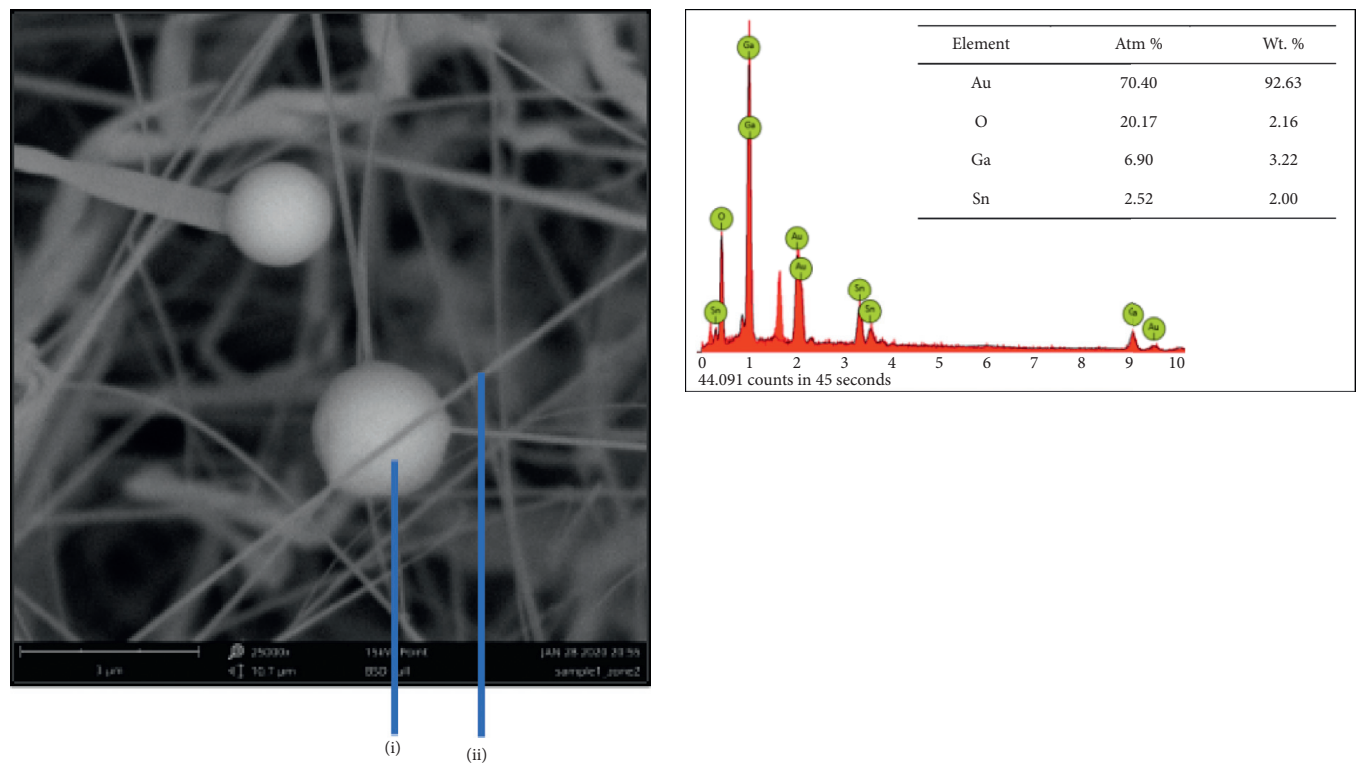

(a)

(b)

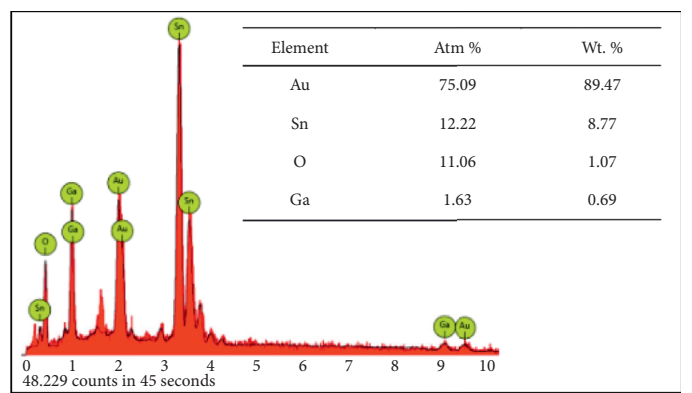

(c)

FIGURE 7: (a) Zone 2 SEM image of the (i) globule and (ii) nanostructure, and EDX spectrum of the (b) nanostructure and (c) globule of sample B.

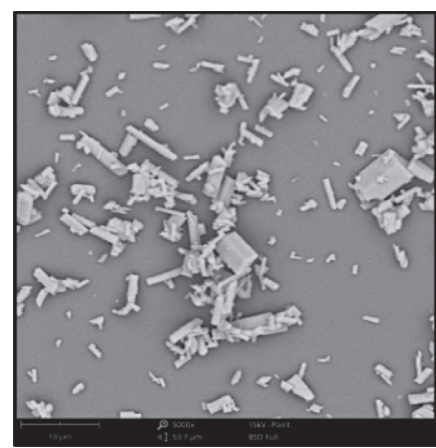

(a)

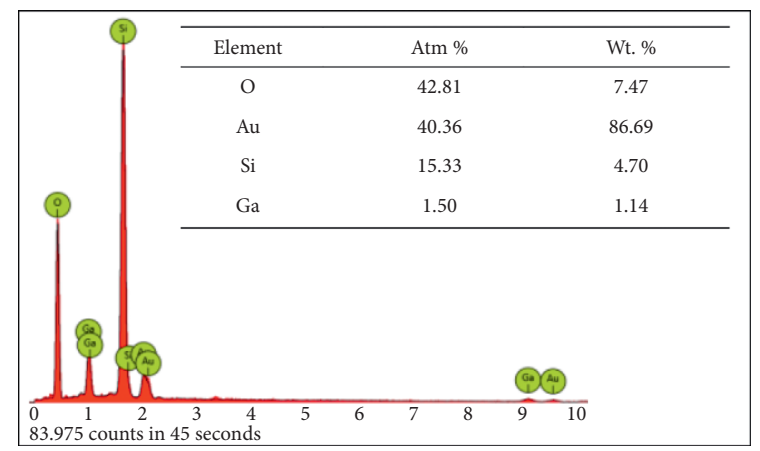

(b)

Figure 8: Zone 3. (a) SEM image and (b) EDX spectra of sample B.

composition was $\mathrm{Ga}$ with $13.06 \mathrm{~atm} \%$ and a lesser concentration of Sn of $1.74 \%$. O had a $21.10 \%$ share, which led to a $\mathrm{Ga}$ to $\mathrm{O}$ ratio of $2: 3$. Conversely, the major component of the globules was $\mathrm{Sn}$ with $24.89 \%$ as supported by its higher EDX peak in Figure 16(c) compared with Ga and O. Ga and O compositions had $4.79 \%$ and $22.11 \%$ shares, respectively, leading to $\mathrm{Ga}$ to $\mathrm{O}$ ratio of $2: 9$.
3.2. Polytype Analysis. According to [17], $142 \mathrm{~cm}^{-1}$ and $179.69 \mathrm{~cm}^{-1}$ low modes were attributed to the vibration and translation of doubly connected straight chains of $\mathrm{GaO}_{6}$ octahedra. The Raman modes at $449.87 \mathrm{~cm}^{-1}$ and $477.68 \mathrm{~cm}^{-1}$ according to $[22,38]$, respectively, were related to the deformation of $\mathrm{GaO}_{6}$ octahedra. The group of Raman modes located at $632.31 \mathrm{~cm}^{-1}$ and $650.67 \mathrm{~cm}^{-1}$ represents the 


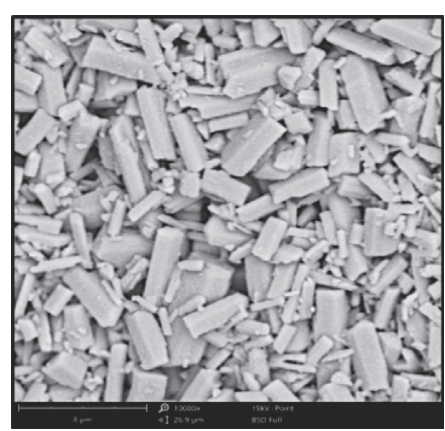

(a)

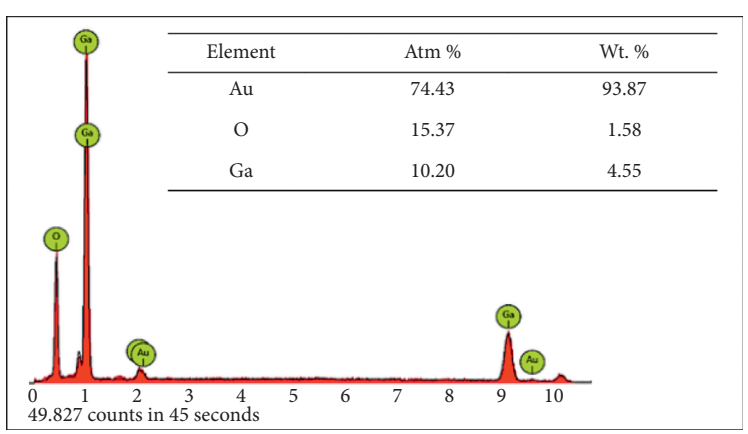

(b)

FIgURe 9: Zone 1. (a) SEM image at 6,500x magnification and (b) EDX spectra of sample C.

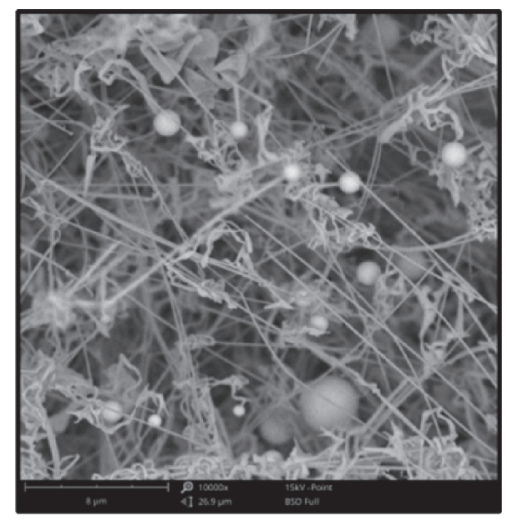

(a)

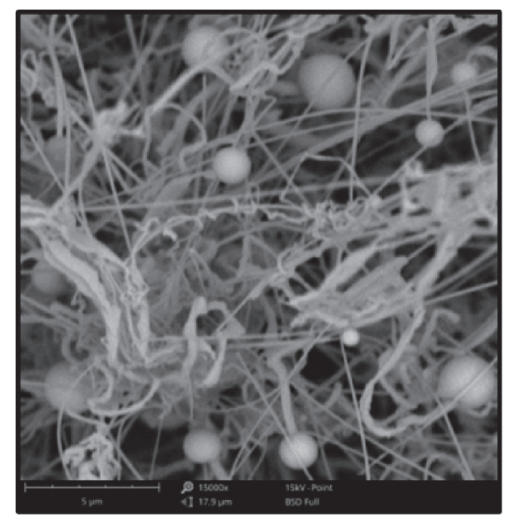

(b)

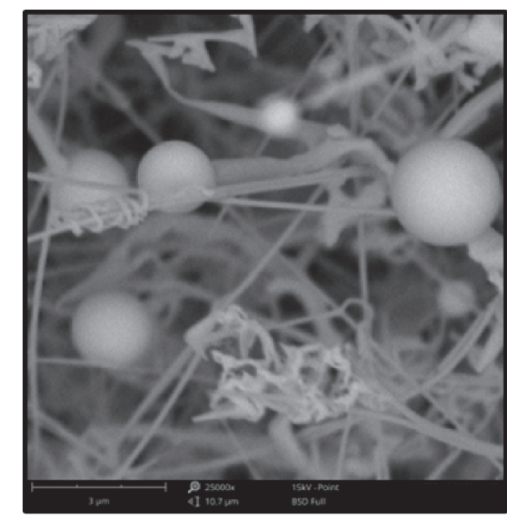

(c)

Figure 10: Zone 2 SEM images of sample C at (a) 10,000x, (b) 15,000x, and (c) 25,000x magnification.

stretching and bending of $\mathrm{GaO}_{4}$. The spectrum of $\mathrm{SiO}_{2}$ at $521.81 \mathrm{~cm}^{-1}$ appeared in Figure 17.

As noticed in Figure 18, only 1 low peak of $\beta$ phase was observed, particularly at $160.73 \mathrm{~cm}^{-1}$, in agreement with [39]. However, the peaks of the deformation of $\mathrm{GaO}_{6}$ octahedra dominated this sample located at $349.02 \mathrm{~cm}^{-1}$, $419.52 \mathrm{~cm}^{-1}$, and $470.89 \mathrm{~cm}^{-1}$. On the other hand, 2 high spectra were located at $627.86 \mathrm{~cm}^{-1}$ and $661.81 \mathrm{~cm}^{-1}$ resulting in the distortion of $\mathrm{Ga}_{2} \mathrm{O}_{3}$ caused by the presence of $\mathrm{Sn}$. Nonetheless, 1 peak of $\varepsilon-\mathrm{Ga}_{2} \mathrm{O}_{3}$ was observed at $714.93 \mathrm{~cm}^{-1}$ as a result of adding $\mathrm{SnO}_{2}$ to $\mathrm{Ga}_{2} \mathrm{O}_{3}$. The peak of $\mathrm{SnO}_{2}$ was not observed in this concentration due to its small concentration [22].

Figure 19 reveals 3 mid peaks at $302.04 \mathrm{~cm}^{-1}$, $317.60 \mathrm{~cm}^{-1}$, and $348.62 \mathrm{~cm}^{-1}$ and 2 high peaks at $662.61 \mathrm{~cm}^{-1}$ and $759.87 \mathrm{~cm}^{-1}$. According to [22], the Raman peak located at $662.61 \mathrm{~cm}^{-1}$ indicates that the majority of the nanostructures grew in [010] direction, which exhibits the highest electrical conductivity for $\beta-\mathrm{Ga}_{2} \mathrm{O}_{3}$ nanowires. Similar to sample B, 1 peak of $\varepsilon-\mathrm{Ga}_{2} \mathrm{O}_{3}$ was noticed at $211.25 \mathrm{~cm}^{-1}$ as reported in the previous study [40]. Conversely, 2 peaks of rutile $\mathrm{SnO}_{2}$ were analyzed at $473.25 \mathrm{~cm}^{-1}$ and $486.42 \mathrm{~cm}^{-1}$. The $473.25 \mathrm{~cm}^{-1}$ peaks confirmed the rutile-type $\mathrm{SnO}_{2}$ single crystal, while $486.42 \mathrm{~cm}^{-1}$ was attributed to lower wavenumbers as the nanoparticle's size decreased.
Sample D showed 1 peak of $\beta-\mathrm{Ga}_{2} \mathrm{O}_{3}$ for the low and mid modes, particularly at $159.60 \mathrm{~cm}^{-1}$ and $415.88 \mathrm{~cm}^{-1}$, respectively, as spotted in Figure 20. Raman peak located at $662.62 \mathrm{~cm}^{-1}$ was likewise observed. No other peaks of the $\mathrm{Ga}_{2} \mathrm{O}_{3}$ phases were detected in this concentration. On the other hand, 2 peaks of $\mathrm{SnO}_{2}$ were seen specifically: $493.84 \mathrm{~cm}^{-1}$, which appeared as the consequence of disorder activation in its rutile structure, and $638.73 \mathrm{~cm}^{-1}$, which corresponds to the classical vibration modes as shown in [41].

\subsection{Electrical Properties for Potential Power Electronics} Application. The I-V curves shown in Figures 21(a) and 21(b) were almost straight and similar to the graph of a resistor and the as-grown $\mathrm{Ga}_{2} \mathrm{O}_{3}$, which is in good agreement with the previous research [42]. On the other hand, Figure 21(c) shows resemblance to the I-V curve of a diode and a single $\mathrm{Sn}$-doped $\mathrm{Ga}_{2} \mathrm{O}_{3}$ in relation to [42].

The shifting of the $\mathrm{I}-\mathrm{V}$ graph of specimen $\mathrm{C}$ implied that there was an enormous increase in its conductivity. This was consistent with other works on $\mathrm{Ga}_{2} \mathrm{O}_{3}$ nanowires in which a strong enhancement of the electrical conductivity was observed due to the incorporation of $S n$ [42]. Nevertheless, the measured currents for sample D, shown in Figure 21(d), ranged from $-1.888 \times 10^{3} \mathrm{nA}$ to $1.827 \times 10^{3} \mathrm{nA}$ and were found to have the 


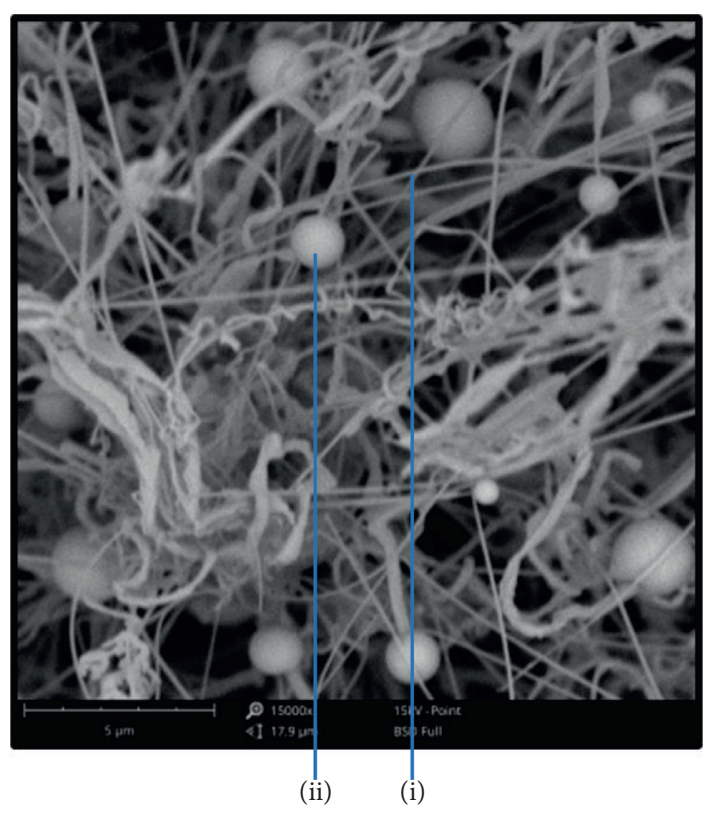

(a)

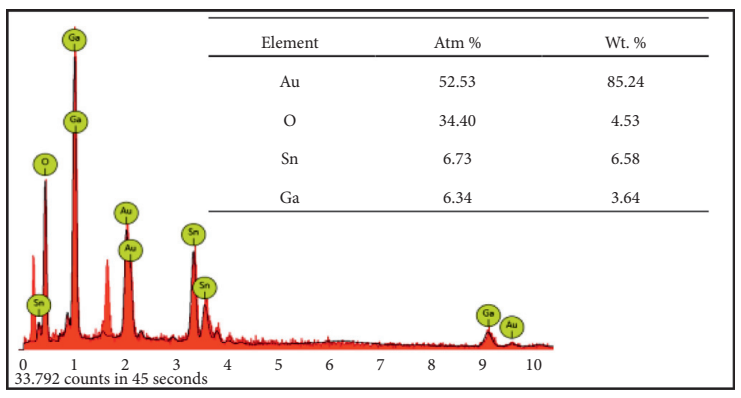

(b)

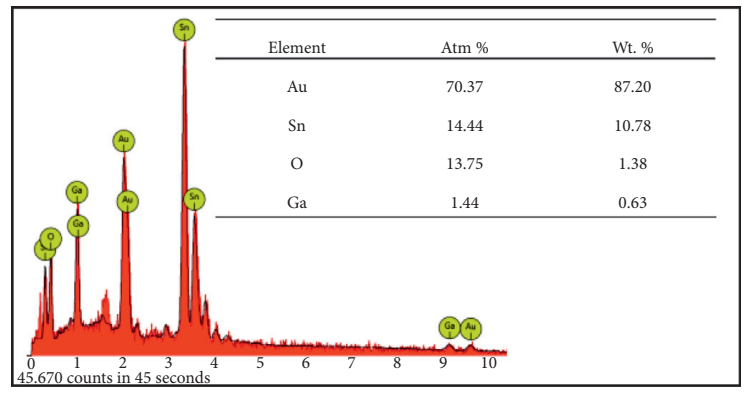

(c)

FIgure 11: (a) Assessed zone 2 SEM image of the (i) nanostructure and (ii) globule, and EDX spectrum of the (b) nanostructure and (c) globule of sample C.

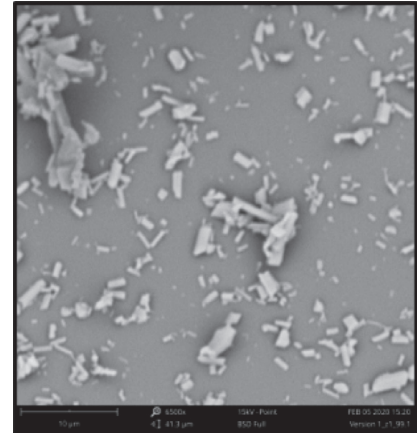

(a)

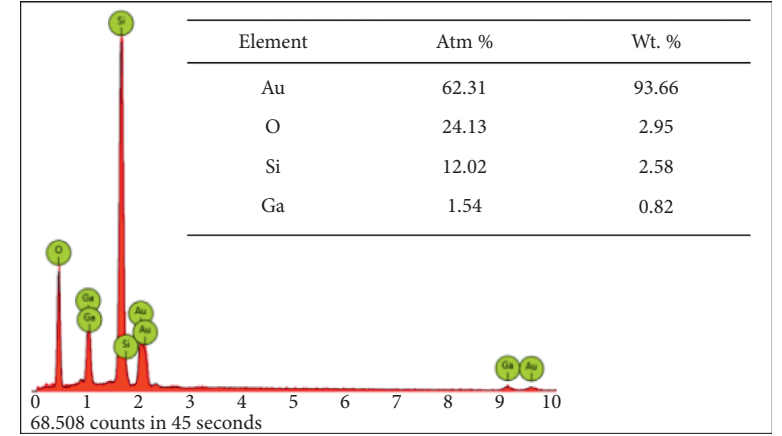

(b)

Figure 12: Zone 3. (a) SEM image and (b) EDX spectra of sample C.

greatest correlation among the other specimens. This sample was expected to have the greatest increase in electrical conductivity since it has the greatest concentration of Sn. However, the length of the contacts attached to this during the 2-point probe test might affect the result.
As can be gleaned in Table 1, the resistivity of sample A was higher compared to the reported value of $1.43 \times 10^{-1} \Omega \cdot \mathrm{cm}$ in [24]. Conversely, the resistivity of sample B was found to be $2.01757 \times 10^{-1} \Omega \cdot \mathrm{cm}$. There was a slight decrease in the resistivity since a very small amount of 


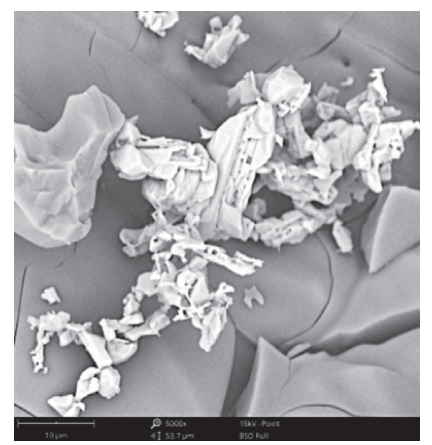

(a)

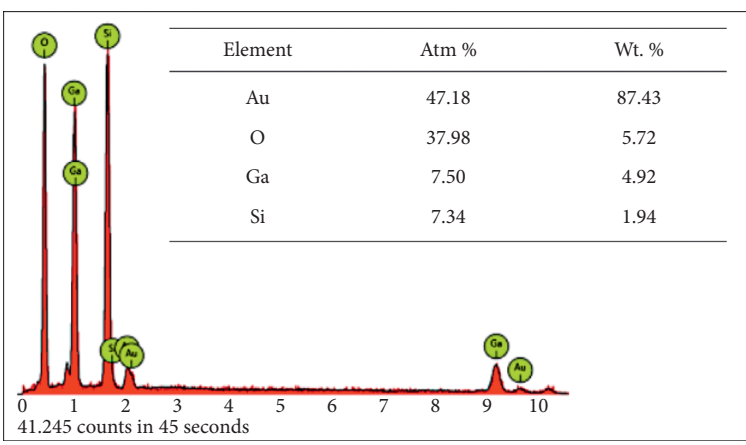

(b)

Figure 13: Zone 1. (a) SEM image and (b) EDX spectra of sample D.

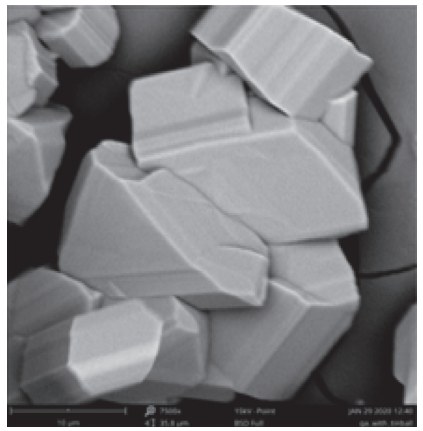

(a)

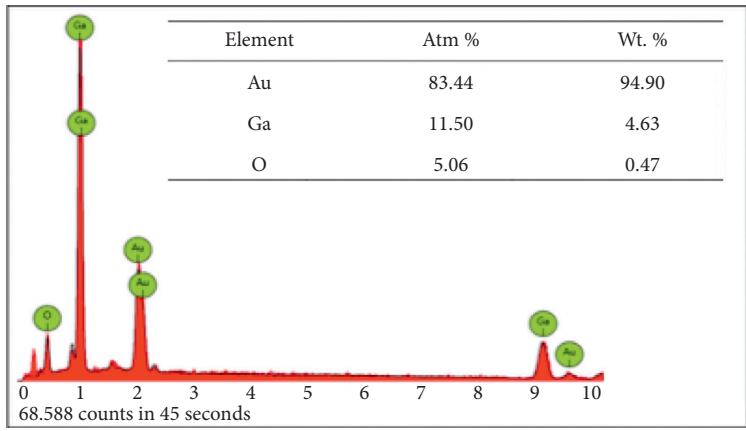

(b)

Figure 14: Zone 2. (a) SEM image and (b) EDX spectra of sample D.

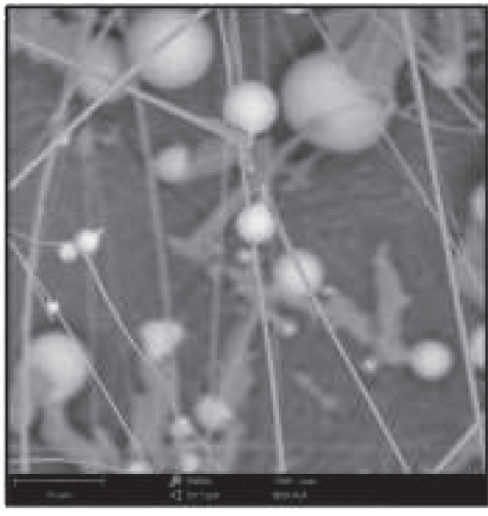

(a)

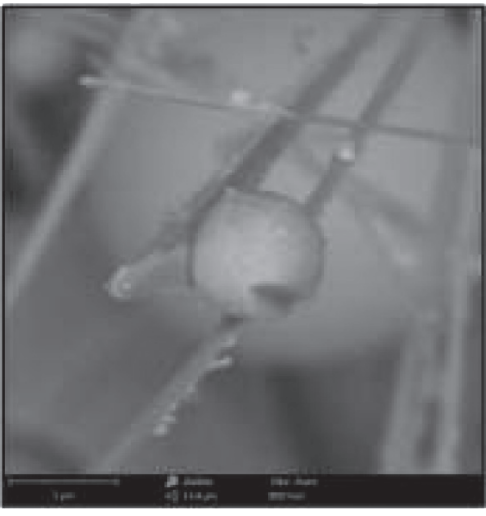

(b)

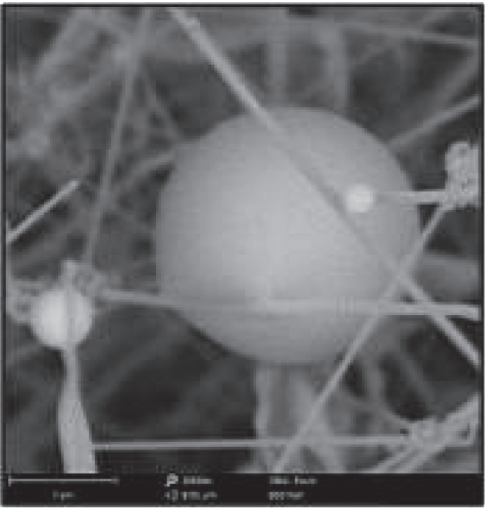

(c)

Figure 15: Zone 3 SEM images of sample D at (a) 5,000x, (b) 20,000x, and (c) 30,000x magnification.

$\mathrm{SnO}_{2}$ was added to $\mathrm{Ga}_{2} \mathrm{O}_{3}$. An increase of $1.15328 \mathrm{~S} / \mathrm{cm}$ was still observed, which proved that the incorporation of $\mathrm{SnO}_{2}$ increases the conductivity of the resistive $\mathrm{Ga}_{2} \mathrm{O}_{3}$. Smaller resistivity of $1.67619 \Omega \cdot \mathrm{cm}$ was observed in sample $\mathrm{C}$ compared to that of $\mathrm{A}$ and $\mathrm{B}$. The conductivity increased by approximately $2.162714 \mathrm{~S} / \mathrm{cm}$ and $1.0094 \mathrm{~S} / \mathrm{cm}$ for samples A and $\mathrm{B}$, respectively. As discussed in the previous research, when $\mathrm{Sn}^{+4}$ substitutes $\mathrm{Ga}^{3+}$ on the octahedral site, it donates an electron to the $\mathrm{Ga}_{2} \mathrm{O}_{3}$ lattice which increases the carrier concentration and thus conductivity [43]. The data obtained in sample $\mathrm{C}$ was clear evidence that the chosen dopant increased the conductivity of $\mathrm{Ga}_{2} \mathrm{O}_{3}$. Another sample proved this information since there was a drastic increase in conductivity in sample D. It was analyzed that the increase resulted in $10.596741 \mathrm{~S} / \mathrm{cm}$ for sample A, $9.443455 \mathrm{~S} / \mathrm{cm}$ for sample $\mathrm{B}$, and $8.434027 \mathrm{~S} / \mathrm{cm}$ for sample $\mathrm{C}$. The mentioned resistivities of $\mathrm{Ga}_{2} \mathrm{O}_{3} / \mathrm{SnO}_{2}$ specimens fell on the range of $10^{-3}$ to $10^{12} \Omega \mathrm{cm}$ with changing doping concentration, which was in good agreement with [11]. The conductivity of the specimens might be affected by the Au sputtering; 


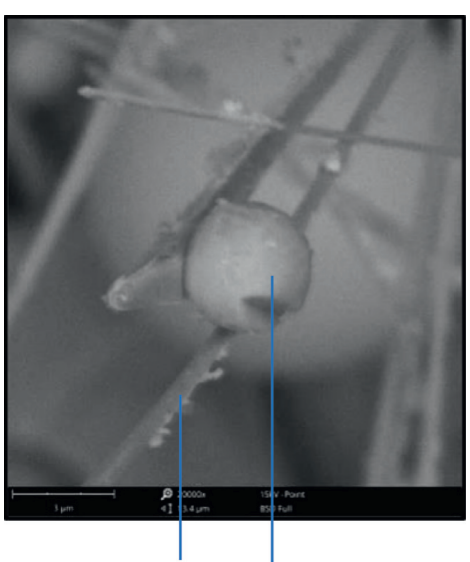

(i)

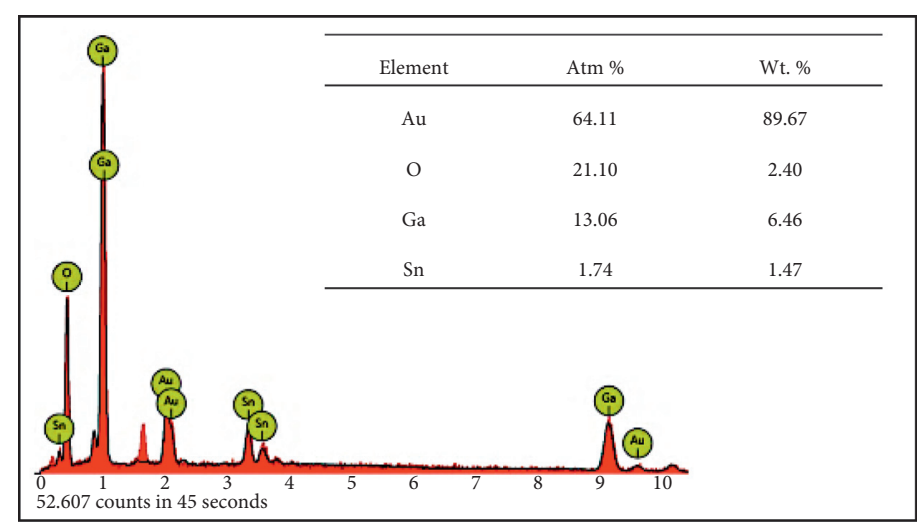

(b)

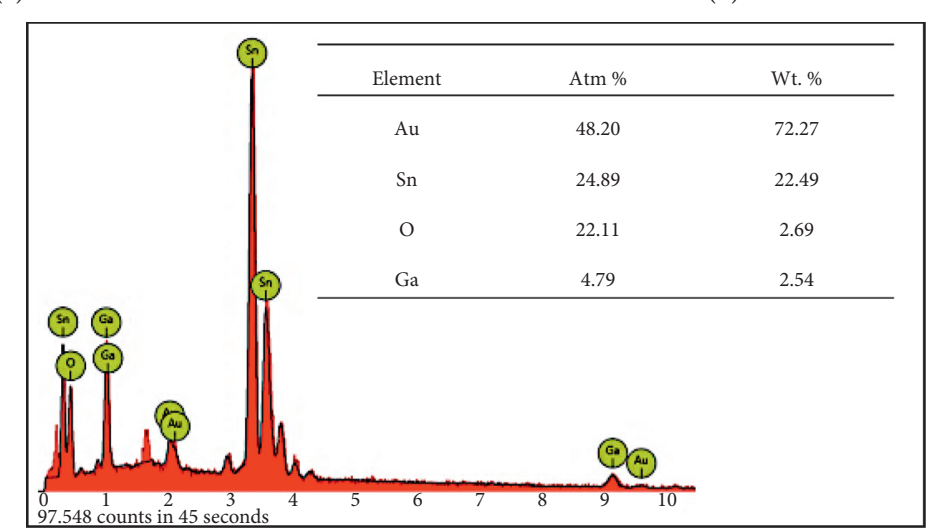

(c)

FIgURE 16: (a) Assessed zone 3 SEM image of the (i) nanostructure and (ii) globule and EDX spectrum of the (b) nanostructure and (c) globule of sample D.

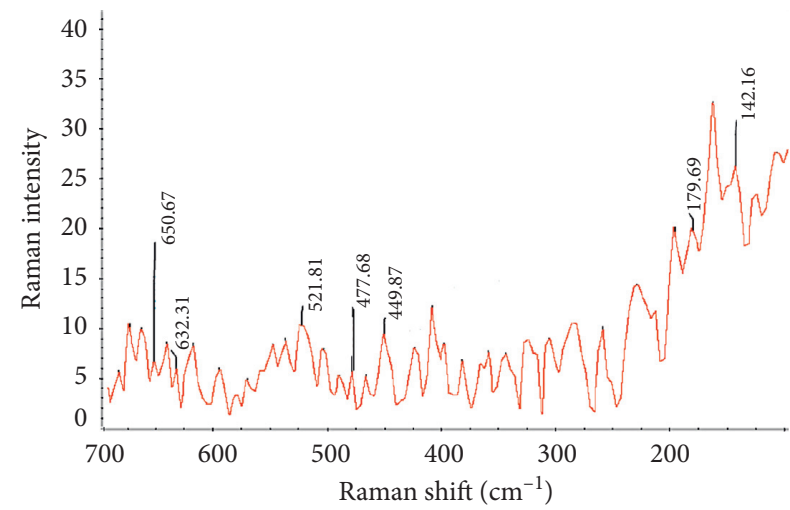

FIgURE 17: Raman spectra of sample A, zone 2 showing 2 low, mid, and high $\beta-\mathrm{Ga}_{2} \mathrm{O}_{3}$ modes and $\mathrm{SiO}_{2}$ peak.

however, its effect was assumed to be the same throughout the specimens.

The as-grown $\beta-\mathrm{Ga}_{2} \mathrm{O}_{3}$ has $\mathrm{n}$-type with a carrier concentration of $1.1053 \times 10^{18} \mathrm{~cm}^{-3}$ and mobility of $21.4752 \mathrm{~cm}^{2} / \mathrm{V} \cdot \mathrm{s}$ at RT. Greater carrier concentration was

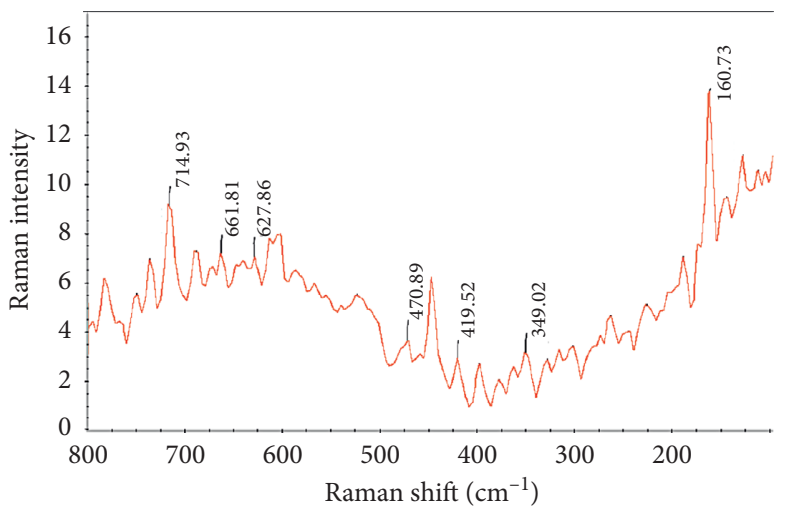

FIgURE 18: Raman spectra of sample B, zone 2 showing 1 low, 3 mid, and 2 high $\beta-\mathrm{Ga}_{2} \mathrm{O}_{3}$ modes and 1 peak of $\varepsilon-\mathrm{Ga}_{2} \mathrm{O}_{3}$.

analyzed in sample B compared with sample A with $2.5791 \times 10^{18} \mathrm{~cm}^{-3}$, while its bulk mobility was compensated with the lowest value of $11.9946 \mathrm{~cm}^{2 /} \mathrm{V} \cdot \mathrm{s}$ among the $\mathrm{Ga}_{2} \mathrm{O}_{3} / \mathrm{SnO}_{2}$ samples. As per Table 1 , sample $\mathrm{D}$ has the greatest mobility of $69.6956 \mathrm{~cm}^{2} / \mathrm{V} \cdot \mathrm{s}$ among the other 


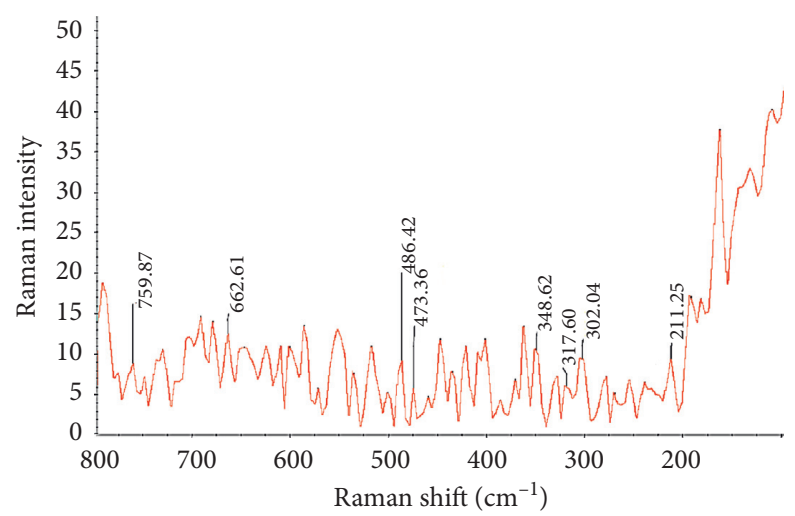

Figure 19: Raman spectra of sample $\mathrm{C}$, zone 2 showing 3 mid and 2 high $\beta-\mathrm{Ga}_{2} \mathrm{O}_{3}$ modes, 1 peak of $\varepsilon$ - $\mathrm{Ga}_{2} \mathrm{O}_{3}$, and 2 rutile peaks of $\mathrm{SnO} \mathrm{O}_{2}$.

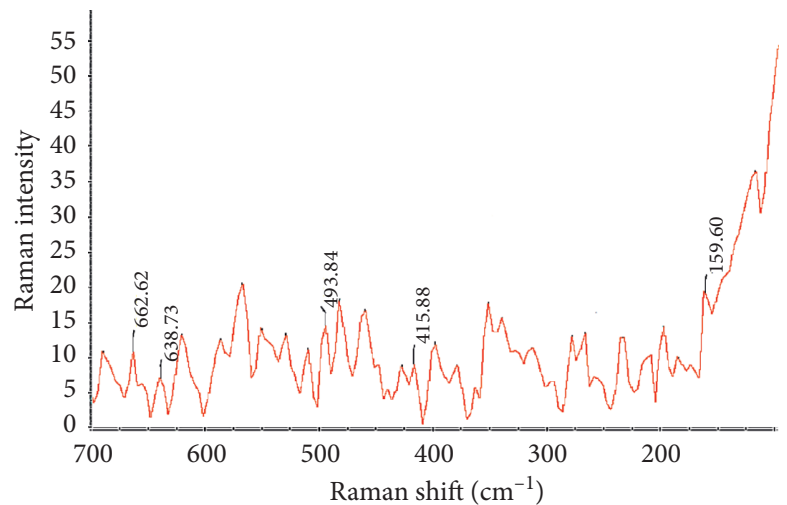

Figure 20: Raman spectra of sample D, zone 3 showing 1 low, mid, and high $\beta-\mathrm{Ga}_{2} \mathrm{O}_{3}$ modes and 2 peaks of $\mathrm{SnO}_{2}$.

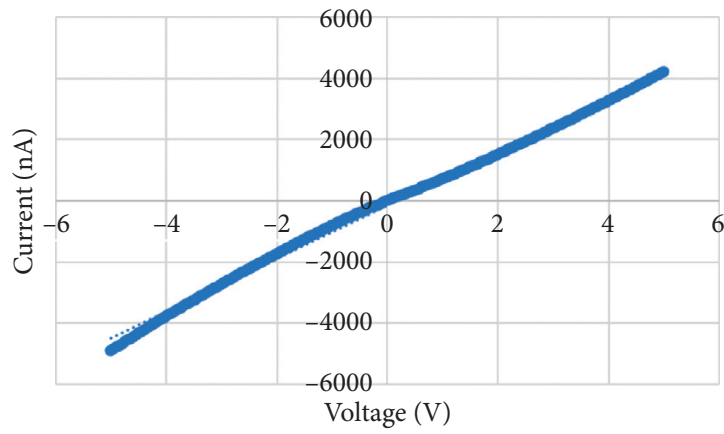

(a)

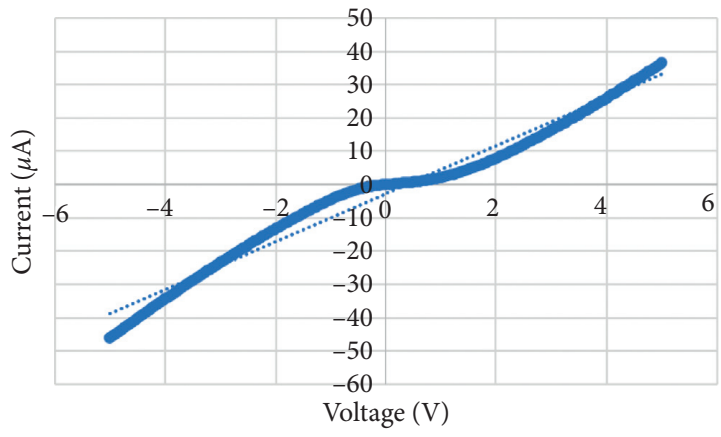

(c)

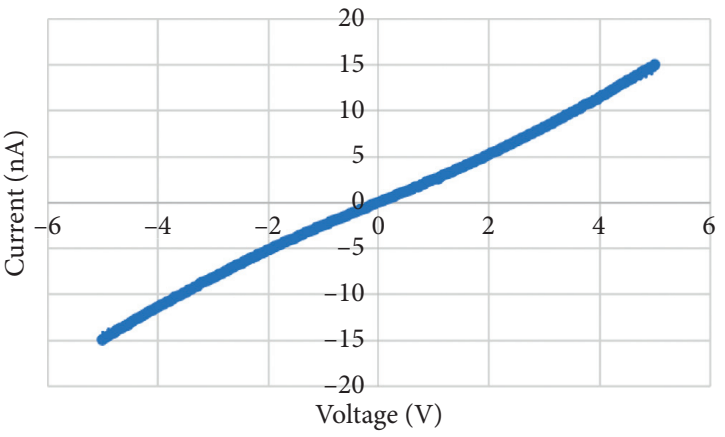

(b)

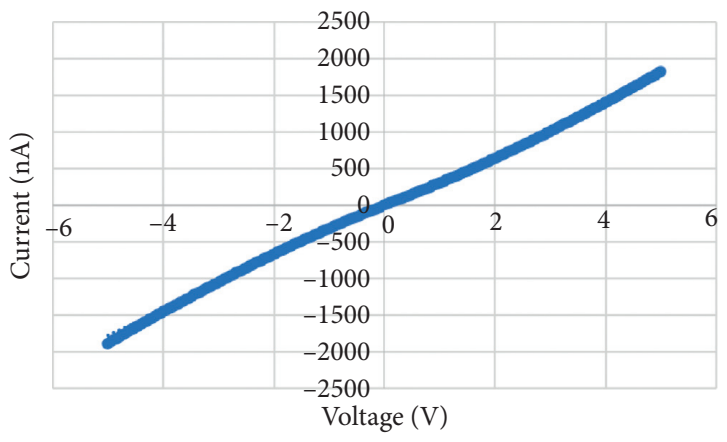

(d)

FIGURE 21: I-V characteristics of samples (a) A, (b) B, (c) C, and (d) D, where nanostructures formed. 
TABle 1: Result of Hall effect and electrical resistivity measurements using van der Pauw method at RT.

\begin{tabular}{lcccc}
\hline Sample & Carrier type & Resistivity $\rho(\Omega \cdot \mathrm{cm})$ & Carrier concentration $n\left(\mathrm{~cm}^{-3}\right)$ & $\mathrm{Mobility} \mu\left(\mathrm{cm}^{2} / \mathrm{V} \cdot \mathrm{s}\right)$ \\
\hline A & $n$ & $2.62938 \times 10^{-1}$ & $1.1053 \times 10^{18}$ & 21.4752 \\
B & $n$ & $2.01757 \times 10^{-1}$ & $2.5791 \times 10^{18}$ & 11.9946 \\
C & $n$ & $1.67619 \times 10^{-1}$ & $1.9344 \times 10^{18}$ & 19.2499 \\
D & $n$ & $6.94449 \times 10^{-2}$ & $1.2896 \times 10^{18}$ & 69.6956 \\
\hline
\end{tabular}

TABle 2: Power loss and specific on-resistance of the samples for potential power electronics application.

\begin{tabular}{lcc}
\hline Sample & Power loss $P_{\text {loss }}(\mathrm{W})$ & $\begin{array}{c}\text { Specific on-resistance } \\
R_{\mathrm{ON}, \mathrm{sp}}\left(\Omega \cdot \mathrm{cm}^{2}\right)\end{array}$ \\
\hline $\mathrm{A}$ & $1.3147 \times 10^{-5}$ & $4.2070 \times 10^{-1}$ \\
$\mathrm{~B}$ & $1.2610 \times 10^{-5}$ & $1.5132 \times 10^{-1}$ \\
$\mathrm{C}$ & $1.0476 \times 10^{-5}$ & $4.6095 \times 10^{-1}$ \\
$\mathrm{D}$ & $4.3403 \times 10^{-6}$ & $8.6806 \times 10^{-2}$ \\
\hline
\end{tabular}

synthesized $\mathrm{Ga}_{2} \mathrm{O}_{3} / \mathrm{SnO}_{2}$ specimens. The carrier density increases to the order of 100 times as the Sn-concentration increases, implying that the electrical resistivity and the carrier concentration of $\beta-\mathrm{Ga}_{2} \mathrm{O}_{3}$ can be controlled by $\mathrm{Sn}$ doping in the range of $10^{16}$ to $10^{18} \mathrm{~cm}^{-3}$ [24].

As per Table 2, sample D showed the smallest power loss with $4.3403 \times 10^{-6} \mathrm{~W}$ compared with samples B and $\mathrm{C}$ with $1.2610 \times 10^{-5} \mathrm{~W}$ and $1.0476 \times 10^{-5} \mathrm{~W}$, respectively. Sample A had the greatest power loss compared to the three samples with $\mathrm{SnO}_{2}$. Sample $\mathrm{D}$ had the least conduction loss due to its low specific on-resistance among the $\mathrm{Ga}_{2} \mathrm{O}_{3} / \mathrm{SnO}_{2}$ specimens.

\section{Conclusions}

The result of this study highlighted that the HVPG technique was effective in the production of different nanostructures. The as-grown $\mathrm{Ga}_{2} \mathrm{O}_{3}$ nanowires were produced with an average diameter of $90.976 \mathrm{~nm}$. When $\mathrm{SnO}_{2}$ was mixed up, the appearance of globules was apparent indicating the presence of $\mathrm{Sn}$ in the samples.

There was a direct correspondence on the size of nanostructures and globules to the concentration of $\mathrm{Ga}_{2} \mathrm{O}_{3}$ and $\mathrm{SnO}_{2}$ as observed in the SEM images. When the concentration of $\mathrm{SnO}_{2}$ was increased, the size of the nanostructures likewise increased and the appearance of the globules became more apparent. A large amount of $\mathrm{SnO}_{2}$ produced more globules, which led to an increase in the size of the nanostructures but decreased on its quantity. Consequently, the globules fell off onto the substrate since the number of nanostructures was not enough to hold them permanently.

EDX findings revealed that both globules and nanostructures were composed of mixed $\mathrm{Ga}, \mathrm{Sn}$, and $\mathrm{O}$ atoms. The major composition of nanostructures was Ga, while the globules were Sn. Nevertheless, the long exposure of the samples to $\mathrm{Au}$ sputtering affected the EDX results.

All $\mathrm{Ga}_{2} \mathrm{O}_{3} / \mathrm{SnO}_{2}$ samples were dominated by Raman peak located at $662 \mathrm{~cm}^{-1}$ and grew at [010] direction, which exhibits the highest electrical conductivity for $\beta-\mathrm{Ga}_{2} \mathrm{O}_{3}$. Doping of $\mathrm{SnO}_{2}$ was proven to unfold the $\varepsilon$ polytype of
$\mathrm{Ga}_{2} \mathrm{O}_{3}$. The rutile peaks of $\mathrm{SnO}_{2}$ and peaks due to its disorder activation were identified in the $\mathrm{Ga}_{2} \mathrm{O}_{3} / \mathrm{SnO}_{2}$ samples.

The I-V curves of the samples showed similarity to the literature. Furthermore, the incorporation of Sn was proven to lower the resistivity of the undoped sample. The decrease in resistivity was attributed to the presence of $\mathrm{Sn}^{+4}$. When some of the $\mathrm{Ga}^{+3}$ ions in the lattice were replaced by $\mathrm{Sn}^{+4}$ or some of the $\mathrm{Sn}$ ions as interstitial atoms were located in the lattice, conduction electrons were produced as supported by the presented Raman data and previous research works. It was likewise clinched that $\mathrm{Ga}_{2} \mathrm{O}_{3} / \mathrm{SnO}_{2}$ has the potential to meet the criteria for the selection of semiconductor substrate suitable for the fabrication of power electronics devices. On the other hand, there was an indirect correspondence between mobility and carrier concentration since the former increased and the latter decreased when the concentration of $\mathrm{SnO}_{2}$ was augmented. For the application, it was concluded that the highest concentration of $\mathrm{SnO}_{2}$ exhibited the lowest power loss and specific on-resistance. It was ascertained that it has the potential to be used for power electronics applications. Future research shall be geared towards the analysis of the mechanical behavior of the $\mathrm{Ga}_{2} \mathrm{O}_{3} / \mathrm{SnO}_{2}$ nanostructures. Also, exploring the p-type and ohmic contacts suitable for $\mathrm{Ga}_{2} \mathrm{O}_{3} / \mathrm{SnO}_{2}$ shall be investigated to realize its full potential for the fabrication of power electronic devices such as the Schottky barrier diode and metal oxide semiconductor field-effect transistor.

\section{Data Availability}

All data used in this manuscript are cited within the article.

\section{Conflicts of Interest}

The authors declare that there are no conflicts of interest regarding the publication of this paper.

\section{Acknowledgments}

The authors would like to express their appreciation to the iNano Lab graduate students, Staffs of the Surface Physics Laboratory, the DLSU College of Science, and Jumar Cadondon for the FTIR micrographs. The publication expenses of this study were funded by the DOST PCIEERD, Commission on Higher Education, DLSU Science Foundation, and iNano.

\section{References}

[1] M. Higashiwaki, H. Murakami, Y. Kumagai, and A. Kuramata, "Current status of $\mathrm{Ga}_{2} \mathrm{O}_{3}$ power devices," 
Japanese Journal of Applied Physics, vol. 55, no. 12, Article ID 1202A1, 2016.

[2] F. Roccaforte, P. Fiorenza, G. Greco et al., "Challenges for energy efficient wide band gap semiconductor power devices," Physica Status Solidi (A), vol. 211, no. 9, pp. 2063-2071, 2014.

[3] E. Chikoidze, A. Fellous, A. Perez-Tomas et al., "P-type $\beta$-gallium oxide: a new perspective for power and optoelectronic devices," Materials Today Physics, vol. 3, pp. 118-126, 2017.

[4] H. Okumura, "Present status and future prospect of widegap semiconductor high-power devices," Japanese Journal of Applied Physics, vol. 45, no. 10A, p. 7565, 2006.

[5] F. Iacopi, M. Van Hove, M. Charles, and K. Endo, "Power electronics with wide bandgap materials: toward greener, more efficient technologies," MRS Bulletin, vol. 40, no. 5, pp. 390-395, 2015.

[6] M. Higashiwaki and G. H. Jessen, "Guest editorial: the dawn of gallium oxide microelectronics," Applied Physics Letter, vol. 112, Article ID 060401, 2018.

[7] K. Sasaki, A. Kuramata, T. Masui, E. G. Villora, K. Shimamura, and S. Yamakoshi, "Device-quality $\beta-\mathrm{Ga}_{2} \mathrm{O}_{3}$ epitaxial films fabricated by ozone molecular beam epitaxy," Applied Physics Express, vol. 5, no. 3, Article ID 035502, 2012.

[8] M. J. Tadjer, J. L. Lyons, N. Nepal, J. A. Freitas, A. D. Koehler, and G. M. Foster, "Editors' choice-review-theory and characterization of doping and defects in $\beta-\mathrm{Ga}_{2} \mathrm{O}_{3}$," ECS Journal of Solid State Science and Technology, vol. 8, no. 7, pp. Q3187Q3194, 2019.

[9] S. J. Pearton, J. Yang, P. H. Cary et al., "A review of $\mathrm{Ga}_{2} \mathrm{O}_{3}$ materials, processing, and devices," Applied Physics Reviews, vol. 5, no. 1, Article ID 011301, 2018.

[10] S. I. Stepanov, V. I. Nikolaev, V. E. Bougrov, and A. E. Romanov, "Gallium oxide: properties and applications-a review," Reviews on Advanced Materials, vol. 44, pp. 63-86, 2016.

[11] H. Xue, Q. Hu, G. Jian, S. Long, T. Pang, and M. Liu, “An overview of the ultrawide bandgap $\mathrm{Ga}_{2} \mathrm{O}_{3}$ semiconductorbased Schottky barrier diode for power electronics application," Nanoscale Research Letters, vol. 13, p. 290, 2018.

[12] B. E. Kananen, L. E. Halliburton, K. T. Stevens, G. K. Foundos, and N. C. Giles, "Gallium vacancies in $\beta-\mathrm{Ga}_{2} \mathrm{O}_{3}$ crystals," Applied Physics Letters, vol. 110, no. 20, Article ID 202104, 2017.

[13] C.-L. Kuo and M. H. Huang, "The growth of ultralong and highly blue luminescent gallium oxide nanowires and nanobelts, and direct horizontal nanowire growth on substrates," Nanotechnology, vol. 19, no. 15, Article ID 155604, 2008.

[14] X. Xiang, C. B. Cao, and H. S. Zhu, "Synthesis and photoluminescence of gallium oxide ultra-long nanowires and thin nanosheets," Journal of Crystal Growth, vol. 279, no. 1-2, pp. 122-128, 2005.

[15] J. B. Varley, J. R. Weber, A. Janotti, and C. G. Van de Walle, "Oxygen vacancies and donor impurities in $\beta-\mathrm{Ga}_{2} \mathrm{O}_{3}$," $A p$ plied Physics Letters, vol. 97, no. 14, Article ID 142106, 2010.

[16] S. Müller, H. von Wenckstern, D. Splith, F. Schmidt, and M. Grundmann, "Control of the conductivity of Si-doped $\beta-\mathrm{Ga}_{2} \mathrm{O}_{3}$ thin films via growth temperature and pressure," Physica Status Solidi (A), vol. 211, no. 1, pp. 34-39, 2013.

[17] D. Gogova, G. Wagner, M. Baldini et al., "Structural properties of $\mathrm{Si}$-doped $\beta-\mathrm{Ga}_{2} \mathrm{O}_{3}$ layers grown by MOVPE," Journal of Crystal Growth, vol. 401, pp. 665-669, 2014.
[18] M. Orita, H. Ohta, M. Hirano, and H. Hosono, "Deep-ultraviolet transparent conductive $\beta-\mathrm{Ga}_{2} \mathrm{O}_{3}$ thin films," Applied Physics Letters, vol. 77, no. 25, pp. 4166-4168, 2000.

[19] E. G. Víllora, K. Shimamura, T. Ujiie, and K. Aoki, "Electrical conductivity and lattice expansion of $\beta-\mathrm{Ga}_{2} \mathrm{O}_{3}$ below room temperature," Applied Physics Letters, vol. 92, no. 20, Article ID 202118, 2008.

[20] X. Zhang, H. Lee, J. Kim, E.-J. Kim, and J. Park, "Solutionprocessed gallium-tin-based oxide semiconductors for thinfilm transistors," Materials, vol. 11, no. 1, p. 46, 2017.

[21] Y.-G. Jang, W.-S. Kim, D.-H. Kim, and S.-H. Hong, "Fabrication of $\mathrm{Ga}_{2} \mathrm{O}_{3} / \mathrm{SnO}_{2}$ core-shell nanowires and their ethanol gas sensing properties," Journal of Materials Research, vol. 26, no. 17, pp. 2322-2327, 2011.

[22] L. Mazeina, Y. N. Picard, S. I. Maximenko et al., "Growth of Sn-doped $\beta-\mathrm{Ga}_{2} \mathrm{O}_{3}$ Nanowires and $\mathrm{Ga}_{2} \mathrm{O}_{3}-\mathrm{SnO}_{2}$ heterostructures for gas sensing applications," Crystal Growth \& Design, vol. 9, no. 10, pp. 4471-4479, 2009.

[23] M. Alonso-Orts, A. M. Sánchez, I. López, E. Nogales, J. Piqueras, and B. Méndez, "3D and 2D growth of $\mathrm{SnO}_{2}$ nanostructures on $\mathrm{Ga}_{2} \mathrm{O}_{3}$ nanowires: synthesis and structural characterization," CrystEngComm, vol. 19, no. 41, pp. 6127-6132, 2017.

[24] N. Suzuki, S. Ohira, M. Tanaka, T. Sugawara, K. Nakajima, and T. Shishido, "Fabrication and characterization of transparent conductive $\mathrm{Sn}$-doped $\beta-\mathrm{Ga}_{2} \mathrm{O}_{3}$ single crystal," Physica Status Solidi (C), vol. 4, no. 7, pp. 2310-2313, 2007.

[25] S. Knight, A. Mock, R. Korlacki et al., "Electron effective mass in Sn-doped monoclinic single crystal $\beta$-gallium oxide determined by mid-infrared optical hall effect," Applied Physics Letters, vol. 112, no. 1, Article ID 012103, 2018.

[26] D. M. De Mesa, G. N. Santos, and R. V. Quiroga, "Synthesis and characterization of $\mathrm{Fe}_{2} \mathrm{O}_{3}$ nanomaterials using Hvpc growth technique for glucose sensing application," International Journal of Scientific \& Engineering Research, vol. 3, no. 8, 2012.

[27] J. C. Briones, G. Castillon, M. P. Delmo, and G. N. C. Santos, "Magnetic-field-enhanced morphology of tin oxide nanomaterials for gas sensing applications," Journal of Nanomaterials, vol. 2017, Article ID 4396723, 2017.

[28] G. N. Santos, A. Salvador, and R. Quiroga, International Journal of Scientific \& Engineering Research, vol. 2, no. 10, 2011.

[29] G. B. Castillon and G. N. C. Santos, "Synthesis and characterizations of $\operatorname{In}_{2} \mathrm{O}_{3}$ nanomaterials," International Journal of Scientific \& Engineering Research, vol. 3, no. 2, 2012.

[30] H. dela Torre and G. N. C. Santos, "Synthesis and characterization of monoclinic gallium oxide nanomaterials for high-concentration ethanol vapor detection," Materials Science and Engineering, vol. 739, Article ID 012031, 2020.

[31] S. I. Maximenko, L. Mazeina, Y. N. Picard, J. A. Freitas, V. M. Bermudez, and S. M. Prokes, "Cathodoluminescence studies of the inhomogeneities in Sn-doped $\mathrm{Ga}_{2} \mathrm{O}_{3}$ Nanowires," Nano Letters, vol. 9, no. 9, pp. 3245-3251, 2009.

[32] I. López, E. Nogales, B. Méndez et al., "Influence of Sn and Cr doping on morphology and luminescence of thermally grown $\mathrm{Ga}_{2} \mathrm{O}_{3}$ nanowires," The Journal of Physical Chemistry $C$, vol. 117, no. 6, pp. 3036-3045, 2013.

[33] T. Matsumura and Y. Sato, "A theoretical study on van der Pauw measurement values of inhomogeneous compound semiconductor thin films," Journal of Modern Physics, vol. 01, no. 05 , pp. 340-347, 2010.

[34] N. D. Cuong, Y. W. Park, and S. G. Yoon, "Microstructural and electrical properties of $\mathrm{Ga}_{2} \mathrm{O}_{3}$ nanowires grown at various 
temperatures by vapor-liquid-solid technique," Sensors and Actuators B: Chemical, vol. 140, no. 1, pp. 240-244, 2009.

[35] K. F. Cai, S. Shen, C. Yan, and S. Bateman, "Preparation, characterization and formation mechanism of gallium oxide nanowires," Current Applied Physics, vol. 8, no. 3-4, pp. 363-366, 2008.

[36] H. J. Chun, Y. S. Choi, S. Y. Bae et al., "Controlled structure of gallium oxide nanowires," The Journal of Physical Chemistry B, vol. 107, no. 34, pp. 9042-9046, 2003.

[37] G. Jessen, K. Chabak, A. Green et al., "Toward realization of $\mathrm{Ga}_{2} \mathrm{O}_{3}$ for power electronics applications," in Proceedings of the 75th Annual Device Research Conference, pp. 1-2, South Bend, IN, USA, June 2017.

[38] X. Du, Z. Li, C. Luan et al., "Preparation and characterization of Sn-doped $\beta-\mathrm{Ga}_{2} \mathrm{O}_{3}$ homoepitaxial films by MOCVD," Journal of Materials Science, vol. 50, no. 8, pp. 3252-3257, 2015.

[39] Y. H. Gao, Y. Bando, T. Sato, Y. F. Zhang, and X. Q. Gao, "Synthesis, Raman scattering and defects of $\beta-\mathrm{Ga}_{2} \mathrm{O}_{3}$ nanorods," Applied Physics Letters, vol. 81, no. 12, pp. 2267-2269, 2002.

[40] M. Kracht, A. Karg, J. Schörmann et al., "Tin-assisted synthesis of $\epsilon-\mathrm{Ga}_{2} \mathrm{O}_{3}$ by molecular beam epitaxy," Physical Review Applied, vol. 8, Article ID 054002, 2017.

[41] A. Dieguez, A. Romano-Rodriguez, A. Vila, and J. Morante, "The complete Raman spectrum of nanometric $\mathrm{SnO}_{2}$ particles," Journal of Applied Physics, vol. 90, no. 3, 2001.

[42] I. López, A. Castaldini, A. Cavallini, E. Nogales, B. Méndez, and J. Piqueras, " $\beta-\mathrm{Ga}_{2} \mathrm{O}_{3}$ nanowires for an ultraviolet light selective frequency photodetector," Journal of Physics D: Applied Physics, vol. 47, no. 41, Article ID 415101, 2014.

[43] K. Lim, L. T. Schelhas, S. C. Siah et al., "The effect of sub-oxide phases on the transparency of tin-doped gallium oxide," Applied Physics Letters, vol. 109, no. 14, Article ID 141909, 2016. 